Harold A. McAlister and William I. Hankopf (eds.)

\title{
Observational Programme for Classical and CCD Photometry of Visual Double and Multiple Systems
}

\section{E. OBLAK}

Observatoire de Besançon, 41 bis Ave d'Observatoire, F-25044 Besancon CEDEX, France

\section{P. LAMPENS}

Royal Observatory of Belgium, Ringlaan 3, B - 1180 Brussels, Belgium

\section{INTRODUCTION}

Complementary accurate photometric data with astrophysical content are needed for a well-chosen sample of binaries and multiple systems for which good-quality astrometric data already exist or will soon be available. The observational programme, started in the context of the European Network of Laboratories "Visual Double Stars" (Oblak et al. 1992), is therefore based on samples extracted from the "Catalogue des Composantes d'Etoiles Doubles et Multiples" (CCDM, Dommanget, 1989) and reported in Annex 1 (Double and Multiple Systems) of the HIPPARCOS Input Catalogue (C. Turon et al. 1992).

Systems with components in the HIPPARCOS Input Catalogue are selected for which the present photometric information is poor, i.e. not all components have been observed or they have colour indices and/or magnitudes of insufficient quality for extraction of astrophysical quantities (Figure 1).

Observations, performed in various observatories located in both hemispheres, must yield both classical and CCD photometric campaigns.

\section{THE PRESENT STATUS OF THE PHOTOMETRY OF VISUAL DOUBLE STARS}

From inspection of the photometric data mainly available in three different photometric systems ( $U B V R I$, Strömgren, Geneva) contained in the "Catalogue Photométrique des Systèmes Doubles et Multiples" (CPSDM, Oblak, 1988), it appears that: (a) about $33 \%$ have only one component photometrically measured; and (b) about $50 \%$ have only joint photometry.

It furthermore appears that few systems have been completely and homogeneously observed in a unique photometric system: in $U B V: 333$ systems; in $u v b y H \beta: 352$ systems and in Geneva 64 systems have at least 2 components observed in the same photometric system.

\section{SELECTION OF THE SYSTEMS}

The selection was made amongst 11,434 double systems, 1960 triple systems, 536 quadruple systems and 237 multiple systems from Annex 1 of the HIPPARCOS Input Catalogue. 

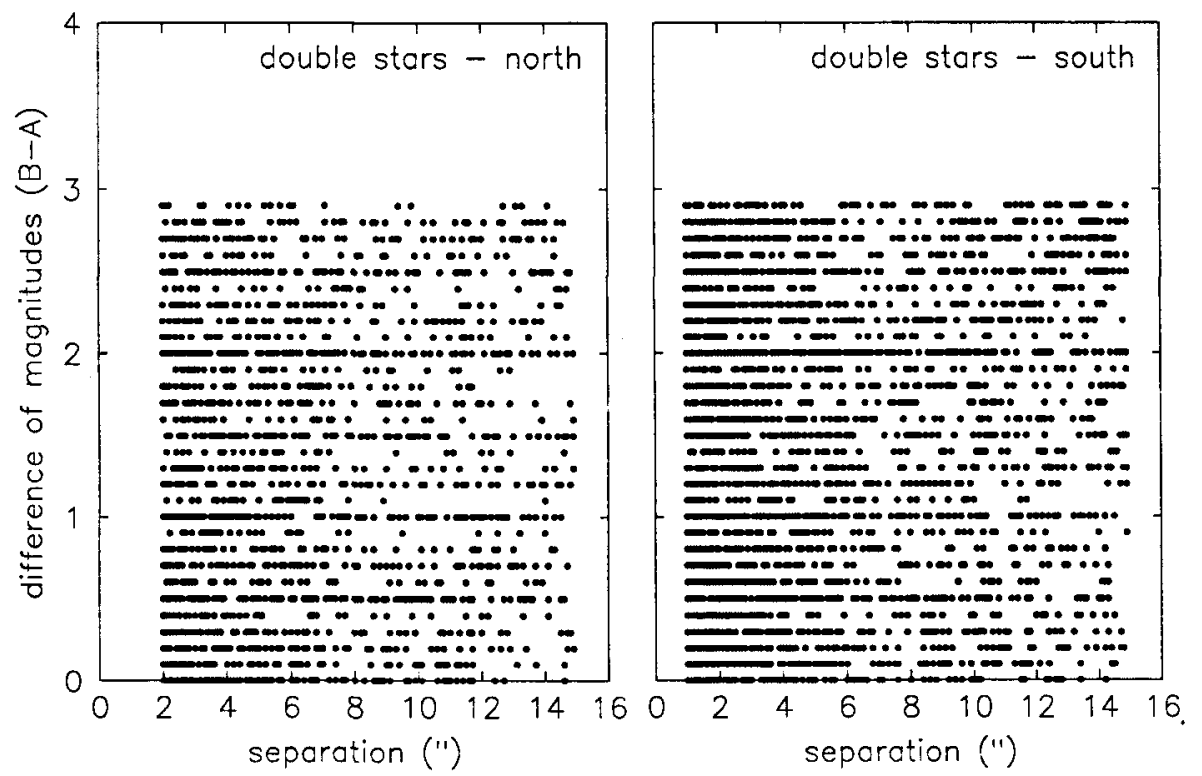

FIGURE 1. Distribution of magnitude difference with separation. Magnitude are from the HD catalogue. This figure illustrates the imprecision of the visual magnitudes since there is a preferential estimation at intervals of one half of a magnitude.

In view of repeated photometric campaigns distributed over both hemispheres the observational programme consists of a northern (declination of the primary component $\delta(\mathrm{A})>-10)$ and a southern sample $(\delta(\mathrm{A}) \leq+10)$. This presentation includes an overlapping region in declination for $-10^{\circ}<\delta(\mathrm{A}) \leq+10^{\circ}$, but only once observed according to feasibility.

Since both classical and CCD photometry are considered, the selection further included splitting according to angular separation and differential magnitude. For separations superior to $12^{\prime \prime}$, individual magnitudes and colours are easily obtained from classical photometry on small telescopes. For small separations, i.e. separations inferior to $15^{\prime \prime}, \mathrm{CCD}$ photometry is more efficient and adequate as long as the difference in magnitude is smaller than three. In addition, some astrometric information is obtained as well.

In this case, the inferior limit is different for the northern and the southern sample since its value reflects the most frequently occurring limitations set by "seeing" at different observatories. The observer then plans his observations in function of the quality of the night.

The overlapping range in separation has been considered for calibration purposes between two very different techniques.

Intersection with the "Catalogue Photométrique des Systèmes Doubles et Multiples" (CPSDM, Oblak, 1988) allowed to identify those sytems lacking individual photometric information. We used a code indicating what systems have photometry for at least two components of the system. The details (component identification, and type of photometric system used) can be inserted later. 
TABLE 1. Observational logbook of past and future campaigns

\begin{tabular}{|c|c|c|c|}
\hline Date & Observer & Observatory & Instrument \\
\hline $\begin{array}{l}\text { February } 90 \\
\text { October } 91 \\
\text { February } 91 \\
\text { April } 91 \\
\text { December } 91 \\
\text { January } 92 \\
\text { March } 92\end{array}$ & $\begin{array}{l}\text { J. CUYPERS } \\
\text { J. CUYPERS } \\
\text { W. SEGGEWISS } \\
\text { P. LAMPENS } \\
\text { E. OBLAK } \\
\text { M. FROESCHLE } \\
\text { P. LAMPENS } \\
\text { E. OBLAK } \\
\text { P. LAMPENS }\end{array}$ & $\begin{array}{l}\text { JF J } \\
\text { ESO } \\
\text { ESO } \\
\text { JFJ } \\
\text { OHP } \\
\text { JFJ J } \\
\text { OHP }\end{array}$ & $\begin{array}{l}70 \mathrm{~cm}+\text { UBVB1B2V1G } \\
90 \mathrm{~cm} \text { Dutch (CCD) + VI } \\
90 \mathrm{~cm} \text { Dutch (CCD) + VI } \\
70 \mathrm{~cm}+\text { UBVB1B2V1G } \\
120 \mathrm{~cm}(\mathrm{CCD})+\mathrm{VI} \\
70 \mathrm{~cm}+\text { UBVB1B2V1G } \\
120 \mathrm{~cm}(\mathrm{CCD})+\mathrm{VI}\end{array}$ \\
\hline $\begin{array}{l}\text { May } 92 \\
\text { August } 92 \\
\text { August } 92\end{array}$ & $\begin{array}{l}\text { J. CUYPERS } \\
\text { P. LAMPENS } \\
\text { E. OBLAK }\end{array}$ & $\begin{array}{l}\text { ESO } \\
\text { ESO } \\
\text { OHP }\end{array}$ & $\begin{array}{l}90 \mathrm{~cm} \text { Dutch (CCD) + VI } \\
50 \mathrm{~cm} \text { ESO + UBVRI } \\
90 \mathrm{~cm} \text { Dutch (CCD) + VI } \\
50 \mathrm{~cm} \text { ESO + UBVRI } \\
120 \mathrm{~cm}(\mathrm{CCD})+\text { VI }\end{array}$ \\
\hline
\end{tabular}

Table 2 summarizes the numbers of systems retained for the observational programme: first, the number of systems with at least one HIC component selected on the basis of the previous criteria, second, the number of systems with at least two components already observed in either of the 3 mentioned photometric systems (code '!') and the number of systems retained for observation. Numbers are given for double, triple, quadruple and multiple systems separately.

\section{OBSERVATIONAL CAMPAIGNS}

Observations have already started or will be performed in various observatories located in both hemispheres: Calar Alto, Jungfraujoch (JFJ), Observatoire de Haute-Provence (OHP), La Palma (LPL) for the northern part and ESO, La Silla, for the southern part (see Table 1).

\section{FORTHCOMING EXTENSIONS}

In order to have a less biased observational programme and to complete in a useful way the photometric data, we intend to introduce the systems not yet reported in the HIC and listed in more recent double star catalogues such as the ones by Couteau (1992) and Worley \& Douglas (1984), Worley ((1989) or its new version?).

We hope to include the new double stars with separations greater than one arcsecond detected in the HIPPARCOS mission.

For a more complete evaluation of multiplicity in our sample, information on spectroscopic and speckle interferometric duplicity will be introduced as well.

The photometric data will be integrated into the data base of the "Centre de Données Astronomiques de Strasbourg". 
TABLE 2. Number of systems from Annex 1 selected for complementary observation

\begin{tabular}{|c|c|c|c|c|c|}
\hline \multicolumn{2}{|c|}{ Sample Criteria } & \multirow{2}{*}{$\begin{array}{r}\text { Double } \\
1607 \\
75 \\
1532\end{array}$} & \multirow{2}{*}{$\begin{array}{r}\text { Triple } \\
201 \\
27 \\
174\end{array}$} & \multirow{2}{*}{$\begin{array}{c}\text { Quadruple } \\
42 \\
10 \\
32\end{array}$} & \multirow{2}{*}{$\begin{array}{r}\text { Multiple } \\
12 \\
5 \\
7\end{array}$} \\
\hline South & $\begin{array}{c}1^{\prime \prime} \leq \rho<15^{\prime \prime} \\
\text { with code! } \\
\text { selected }\end{array}$ & & & & \\
\hline & $\begin{array}{c}\rho \geq 12^{\prime \prime} \\
\text { with code ! } \\
\text { selected }\end{array}$ & $\begin{array}{r}1472 \\
228 \\
1244\end{array}$ & $\begin{array}{r}128 \\
36 \\
92\end{array}$ & $\begin{array}{r}14 \\
6 \\
8\end{array}$ & $\begin{array}{l}4 \\
2 \\
2\end{array}$ \\
\hline \multirow[t]{2}{*}{$\left|\delta_{A}\right|<10$} & $\begin{array}{c}1^{\prime \prime} \leq \rho<15^{\prime \prime} \\
\text { with code! } \\
\text { selected }\end{array}$ & $\begin{array}{r}405 \\
29 \\
376\end{array}$ & $\begin{array}{l}74 \\
12 \\
62\end{array}$ & $\begin{array}{r}24 \\
8 \\
16\end{array}$ & $\begin{array}{r}10 \\
6 \\
4\end{array}$ \\
\hline & $\begin{array}{c}\rho \geq 12^{\prime \prime} \\
\text { with code ! } \\
\text { selected }\end{array}$ & $\begin{array}{r}423 \\
87 \\
336\end{array}$ & $\begin{array}{r}119 \\
44 \\
75\end{array}$ & $\begin{array}{l}25 \\
12 \\
13\end{array}$ & $\begin{array}{l}2 \\
1 \\
1\end{array}$ \\
\hline \multirow[t]{2}{*}{ North } & $\begin{array}{c}2^{\prime \prime} \leq \rho<15^{\prime \prime} \\
\text { with code ! } \\
\text { selected }\end{array}$ & $\begin{array}{r}879 \\
71 \\
808\end{array}$ & $\begin{array}{r}227 \\
41 \\
186\end{array}$ & $\begin{array}{l}70 \\
24 \\
46\end{array}$ & $\begin{array}{l}30 \\
14 \\
16\end{array}$ \\
\hline & $\begin{array}{c}\rho \geq 12^{\prime \prime} \\
\text { with code ! } \\
\text { selected }\end{array}$ & $\begin{array}{r}1354 \\
194 \\
1160\end{array}$ & $\begin{array}{r}359 \\
88 \\
271\end{array}$ & $\begin{array}{r}103 \\
26 \\
77\end{array}$ & $\begin{array}{l}39 \\
16 \\
23\end{array}$ \\
\hline \multirow[t]{2}{*}{ Total } & $\begin{array}{c}\text { CCD } \\
\text { with code! } \\
\text { selected }\end{array}$ & $\begin{array}{r}2891 \\
175 \\
2716\end{array}$ & $\begin{array}{r}502 \\
80 \\
422\end{array}$ & $\begin{array}{r}136 \\
42 \\
94\end{array}$ & $\begin{array}{l}52 \\
25 \\
27\end{array}$ \\
\hline & $\begin{array}{l}\text { Classical } \\
\text { with code ! } \\
\text { selected }\end{array}$ & $\begin{array}{r}3249 \\
509 \\
2740\end{array}$ & $\begin{array}{l}606 \\
168 \\
438\end{array}$ & $\begin{array}{r}142 \\
44 \\
98\end{array}$ & $\begin{array}{l}45 \\
19 \\
26\end{array}$ \\
\hline
\end{tabular}

The systems selected by the criteria marked with * have also to obey the condition $\left|\Delta\left(m_{A}, m_{B}\right)\right|<3$.

In case of a multiple system, one component separation must satisfy $1^{\prime \prime} \leq \rho_{i}<15^{\prime \prime}$ and $\left|\Delta\left(m_{A}, m_{i}\right)\right|<3$.

\section{REFERENCES}

Couteau, P. 1992 in Centre de Données Astronomiques de Strasbourg, in preparation Dommanget, J. 1989, in Star Catalogues: A Centennial Tribute to A.N. Vyssotsky, eds. Philip and Upgren, 77-82.

Oblak, E. 1988, Ap\&SS, 142, 31

Oblak et al. 1992, "The European Network of Laboratories: Visual Double Stars", this Colloquium

Turon, C. et al. 1992, The HIPPARCOS Input Catalogue, ESA SP1136, Vol.6

Worley, C.E. \& Douglas, G.G. 1984, The Washington Double Star Catalog, (Washington, USNO)

Worley, C.E. 1989, Publ. U.S.N.O., Vol. 25 